\title{
Hitherto unknown morphs of Hyperomyzus (Neonasonovia) hieracii (Börner, 1939) (Homoptera: Aphididae)
}

\author{
A.V. Stekolshchikov \& S.V. Buga
}

\begin{abstract}
Stekolshchikov, A.V. \& Buga, S.V. 2006. Hitherto unknown morphs of Hyperomyzus (Neonasonovia) hieracil (Börner, 1939) (Homoptera: Aphididae). Zoosystematica Rossica, 15(1): 57-62.

The species Hyperomyzus (Neonasonovia) hieracii (Bormer, 1939) is found in Russia for the first time. The first descriptions of fundatrix, male and oviparous females of this monoecious species are given.
\end{abstract} A.V. Stekolshchikov, Zoological Institute, Russian Academy of Sciences, Universitetskaya
nab. I. St.Petersburg 199034, Russia.E-mail: aphids@zin.ru

S.V. Buga, Zoological Department, Byelorussian State University, pr. Nezavisimosti 4, Minsh 220030, Republic of Belarus. E-mail: aphids@tut.by

The very rare and poorly known species discussed in this paper was originally described by Bömer (1939) as Rhopalosiphoninus hieracii. Later he (Börner, 1952) placed it in the genus Hyperomyzella H.R.L., but Stroyan (1957) emphasized that this species and Hyperomyzus (Neonasonovia) picridis (Börner \& Blunck, 1916) form a morphological link between Hyperomyzus Börner and Nasonovia Mordv. and placed $H$. hieracii in the subgenus Neonasonovia of the genus Hyperomyzus.

To present day, only solitary finds of this species have been made in Germany and Austria (Börner, 1939, 1952; Bōrner \& Franz, 1956), Great Britain (Stroyan, 1957; Shaw, 1964), Switzerland and Denmark (Heie, 1976, 1994). Tharco (1979) collected aphids very similar to $H$. $(N$.) hieracii in Portugal, but was unable to attribute them to this species with confidence. There are published descriptions of apterous and alate viviparous females only. The life cycle of $H$. hieracii has been unknown until recently, but as early as 1952 Börner suggested that the species is monoecious on Hieracium.

A small colony including 6 fundatrix larvae has been found by A.V. Stekolshchikov on 18.VI. 2004 in the southern part of the Lapland State Biosphere Nature Reserve (Murmansk Prov., Russia) in vicinity of Chuna Lake. It was situated on the underside of young leaves of Hieracium sp. (seemingly, Hieracium vulgatum Fries.). Aphids on the plant have been transferred to laboratory, where an adult fundatrix appeared on 2.VII.2004. Another colony (1 apterous virginopara female and 6 larvae) has been found at the same place on a plant of the same species on 18.VII.2004. Under laboratory conditions, 2 oviparae females appeared on 3-6.VIII.2004.

In the aphidological collection of Institute of Entomology, Czech Academy of Sciences (České Budějovice, Czech Republic), two slides from Dr. H.L.G. Stroyan collection are stored. Dr. Stroyan obtained one viviparous female and one apterous male of $H$. hieracii in laboratory condition in October 1958. Obviously an initial aphid colony has been collected in Tobermory (Scotland, Argyll, Isle of Mull) on 11.DX.1957 (Show, 1964). However, Dr. Stroyan did not publish any description of the male, oviparous female and life cycle of the species. Dr. J. Holman kindly put Dr. Stroyan's slides at our disposal for investigation. Now, we may give description of all previously unknown morphs and conclude that $H$. hieracii has a monoecious life cycle.

In the article, all measurements (always in $\mu \mathrm{m}$ ), number of hairs, rhinaria, etc., and indexes are presented by extreme variants and by arithmetical mean (in brackets). In case when samples differ strongly, minimum and maximum value of arithmetical mean are given in brackets, for example 607-802 (627-795).

\author{
Hyperomyzus (Neonasonovia) hieracil \\ (Bormer, 1939) \\ (Table, Figs 1-11).
}

Materlal. Russla, Murmansk Prov.: 1 fundatrix, sample no. 9285, the Lapland State Biosphere Reserve, near Chuna Lake, bank of river El'yavruay, on young leaves of Hieracium sp., then in culture, 2.VI.2004, A.V. Stekolshchikov; 2 oviparous females, sample no. 9358-3.VII, 


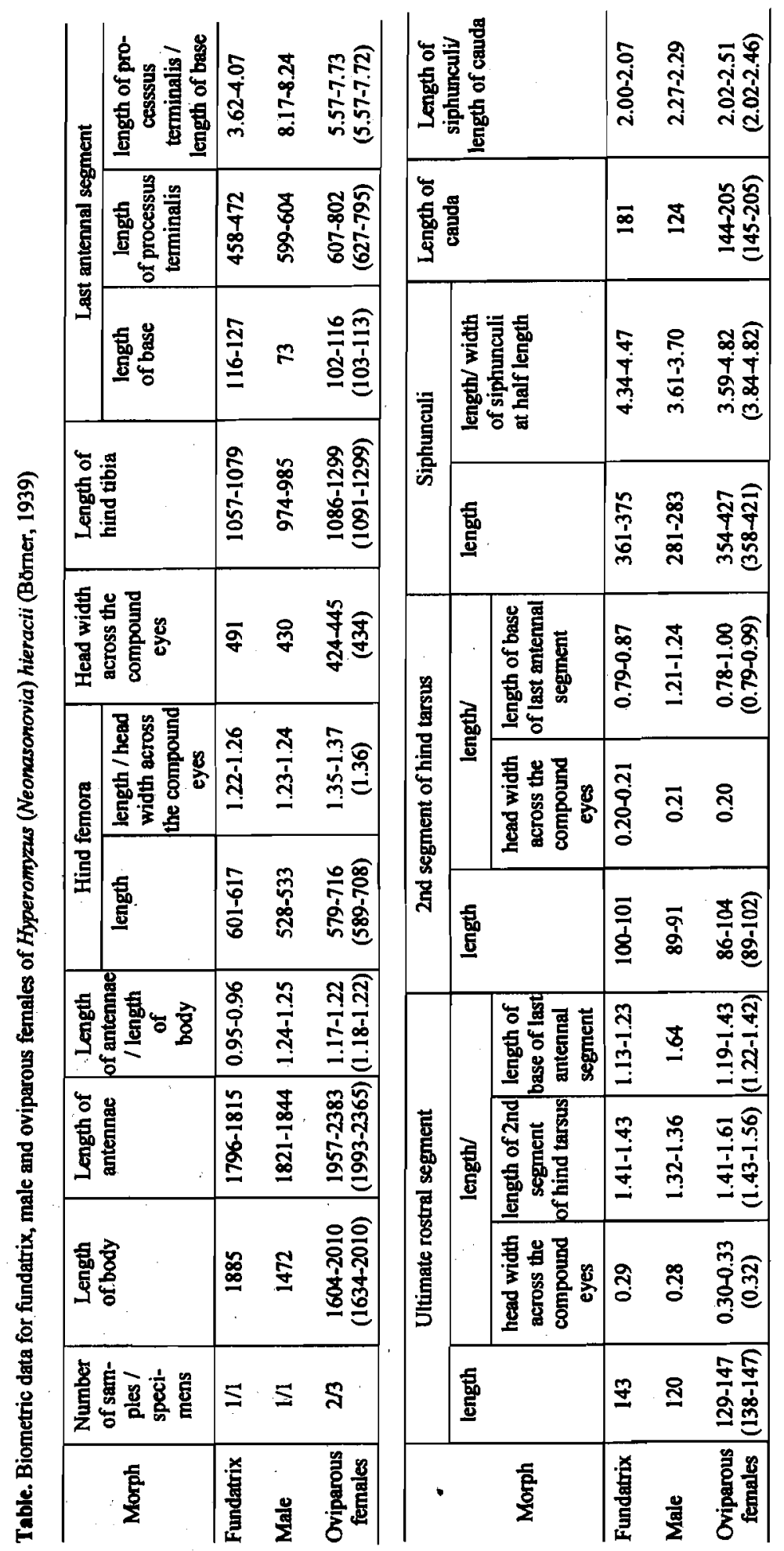


same place as in fundatrix, on pedicle of Hieracium sp., then in culture, 3-6.VIII.2004, A. V. Stekolshchikov. Great Britain, Scotland: 1 oviparous female and 1 apterous male, Argyll, Isle of Mull, Tobermory, near lighthouse, Hieracium sp., then in culture, 2.X.1957 (female) and 14.X.1957 (male), H.L.G Stroyan.

Fundatrix. Elliptic. Colour when alive dark brown, shining; apices of femora grey; antennae (except bases), apices of tibiae and tarsi black; siphunculi dark grey, cauda pale. Cleared specimens with dark brown antennae, apices of femora, bases and apices of tibiae and tarsi, brown head, 3rd and 4th rostral segments, legs, arms of mesostemal furca, bands on segments of thorax, abdominal shield, bands on abdominal tergites V-VII, marginal maculae, peritremes, ante- and postsiphuncular sclerites, siphunculi, subgenital and anal plate and cauda. Dorsal surface of thorax with broad bands on all segments. Abdominal dorsum with large shield on tergites I-IV, bands on tergites V-VII, large marginal sclerites on tergites I-IV, ante- and postsiphuncular sclerites and peritremes. Surface of head, thorax and abdominal tergites I-VI weakly wrinkled, almost smooth, of abdominal tergites VII and of postsiphuncular sclerites with rows of small, pointed spinules, which are partially fused and forming scales on tergites VIII; surface of ventral side of thorax and abdominal sternites I-V smooth, of abdominal sternites VI-VII with long rows of small pointed spinules. Hairs on dorsal surface of thorax and abdomen weakly capitate or blunt, on ventral surface of thorax and abdomen pointed or finely pointed; longest dorsal, marginal and ventral hairs on abdominal tergite III 24, 27 and 40 long, $1.00,1.11$ and 1.67 times as long as articular diameter of $3 \mathrm{rd}$ antennal segment, respectively; abdominal tergite III with 8 dorsal hairs; tergite VI with 4 hairs between siphunculi; tergite VIII with 7 hairs, longest hair 54 long, 2.22 times as long as articular diameter of 3rd antennal segment. Marginal and spinal tubercles absent. Head without epicranial coronal suture. Antennal tubercles not high, diverging, their surface smooth; median tubercle weakly developed; frons moderately concave; ratio of depth of sinus to distance between bases of antennae 0.06. Occipital and frontal hairs weakly capitate, longest occipital and frontal hairs 30 and 27 long, 1.22 and 1.11 times as long as articular diameter of $3 \mathrm{rd}$ antennal segment, respectively. Antennae 6-segmented, 3rd antennal segment with 8-9 secondary rhinaria situated in row all over posterior margin of segment, 4th segment with $0-1,5$ th segment without rhinaria. Surface of 1 st-2nd antennal segments weakly wrinkled, of 3rd segment smooth with small scales at base of segment, of 4th segment weakly imbricated, of 5-6th segments imbricated. Hairs on antennae weakly capitate, on 5-6th segments pointed; longest hair on 3rd segment 27-30 long, 1.11-1.22 times as long as articular diameter of segment; longest hair on basal part of 6 th antennal segment 1.00-1.17 times as long as articular diameter of basal part of segment. Secondary rhinaria elliptical or almost rounded, projecting, with sclerotized rim and more or less convex membrane. Rostrum reaching abdominal segment II. Ultimate rostral segment with 8 long accessory hairs. Legs strong; hind femora and hind tibiae $0.32-0.33$ and $0.56-$ 0.57 times as long as body, respectively, inner side of coxae with rows of small spinules sometimes partially fused and forming scales; trochanters, femora, tibiae and outer sides of hind coxae smooth; 2nd tarsal segments imbricated. Hairs on legs blunt or pointed, rarely weakly capitate or finely pointed; ventral hair on hind trochanter 0.60 times as long as basal diameter of hind femur; longest dorsal, ventral and dorso-apical hairs on hind femur 22-27, 27 and 22-24 long, respectively; longest dorsal hair on hind tibia 1.25-1.50 times as long as mid-diameter of the latter. First tarsal segments with 3,3,3 hairs. 2nd segment of hind tarsus 4.11-4.69 times as long as its maximum width. Siphunculi distinctly swollen (diameter of the swollen part near apex 1.67-1.68 times the smallest diameter of the basal half), with distinct flanges, surface of siphunculi smooth, weakly wrinkled at base. Subgenital plate oval, with 5 pointed hairs on anterior half and 12 hairs along hind margin. Hairs on anal plate finely pointed. Cauda finger-shaped, with 9 finely pointed hairs.

Measurements. Body - $1885 \times 1046$, antennae - 1815: III - 512, $\mathrm{N}$ - 264, V - 251, VI $116+472$; hind trochanter+femur -679 , hind tibia -1057 , siphunculus - $361 \times 81$; cauda $-181 \times$ 121 (at base) $\times 108$ (before base).

Male. Apterous, alatiform. Elongate-elliptic. Colour when alive unknown. Cleared specimens with dark brown head, antennae, 3rd and 4th rostral segments, mesothorax, apices of femora, bases and apices of tibiae and tarsi, with brown proand metatorax, legs, bands on abdominal segments I-IV and VII-VIII, sclerites on tergites VVI, marginal maculae, peritremes, ante- and postsiphuncular sclerites, siphunculi, anal plate and cauda. Abdominal dorsum with large separate bands on tergites I-IV, two sclerites on tergites $V$ and VI, bands on tergites VII-VIII, large marginal sclerites on tergites I-IV and VII, ante- and postsiphuncular sclerites and peritremes. Surface of head, thorax and abdominal tergites I-VI weakly wrinkled, almost smooth, of abdominal tergites VII and of postsiphuncular sclerites with rows of small, pointed spinules, which are on tergites VII partially fused and forming short scales; surface of ventral side of thorax smooth, of abdomen with long rows of small pointed spinules. Hairs on dorsal surface of thorax and abdomen 

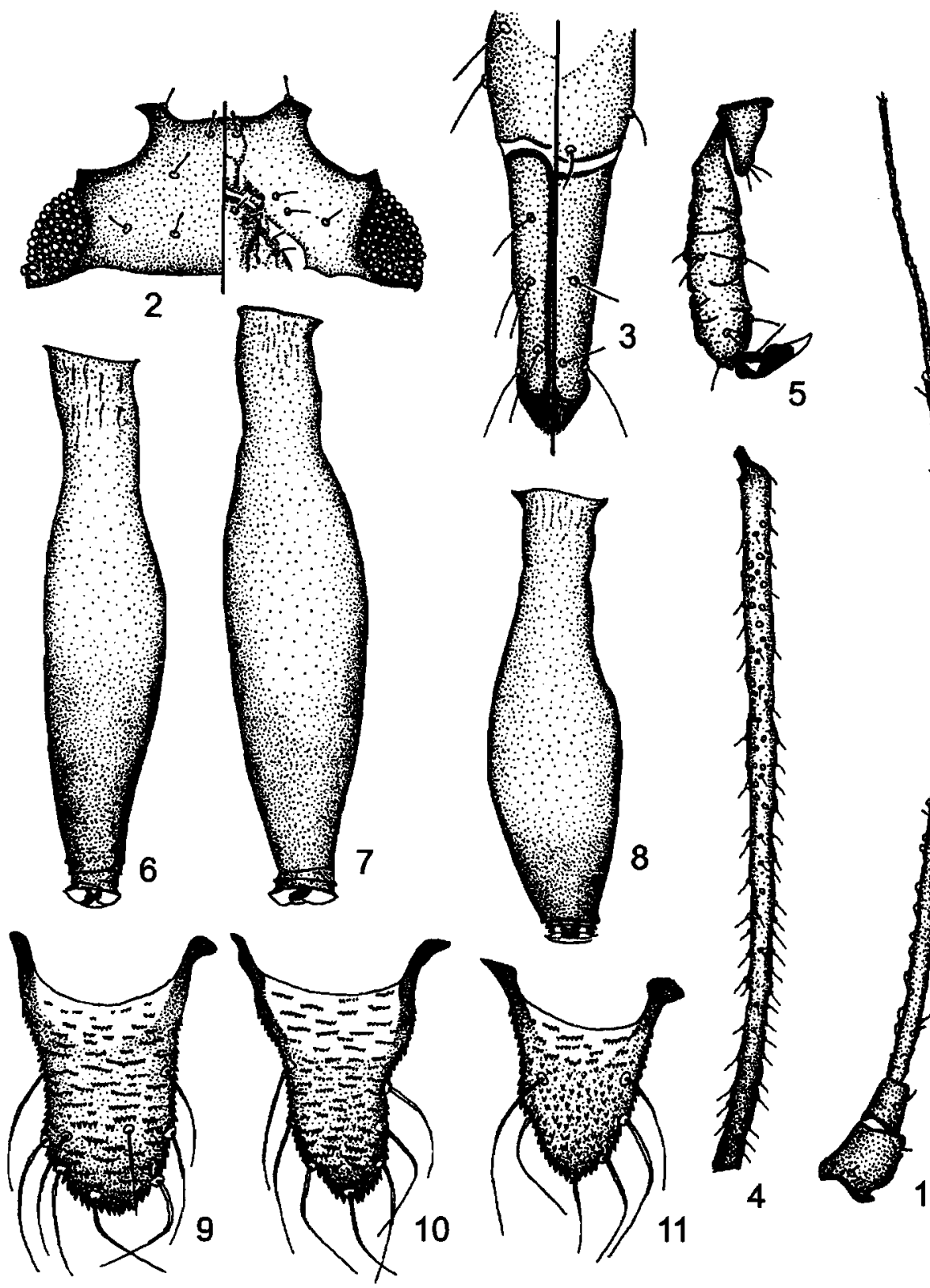

Figs 1-11. Hyperomyzus (Neonasonovia) hieracii. 1, antenna of fundatrix; 2, head of oviparous female; 3, ultimate segment of rostrum; 4 , hind tibia of oviparous female; 5 , hind tarsus of oviparous female; $6-8$, siphunculi $(6$, of fundatrix; 7, of male; 8 , of oviparous female); $9-11$, cauda (9, of fundatrix; 10, of male; 11 , of oviparous female).

blunt, on ventral surface of thorax and abdomen pointed or, rarely, blunt; longest dorsal, marginal and ventral hairs on abdominal tergite III 27 , 25 and 30 long, $0.95,0.91$ and 1.09 times as long as articular diameter of 3rd antennal segment, respectively, abdominal tergite III with 4 dorsal hairs; tergite VI with 3 hairs between siphuncu- li; tergite VIII with 5 hairs, longest hair 40 long, 1.45 times as long as articular diameter of 3rd antennal segment. One marginal tubercle present on each abdominal segment II and III. Spinal tubercles absent. Head without epicranial coronal suture. Antennal tubercles low, diverging; surface of antennal tubercles smooth; median tubercle 
weakly developed; frons moderately concave; ratio of depth of sinus to distance between bases of antennae 0.05 . Occipital and frontal hairs blunt; longest occipital and frontal hairs 33 and 25 long, 1.18 and 0.91 times as long as articular diameter of 3rd antennal segment, respectively. Antennae 6-segmented; 3rd antennal segment with 13-15 secondary rhinaria situated in row all over posterior margin of segment, 4th segment with 4-5, 5th segment with 3 thinaria. Surface of 1st-2nd antennal segments weakly wrinkled, of 3 rd-4th segments smooth with small scales at base of 3rd segment, of 5th segment and base of 6th segment weakly imbricated, surface of processus terminalis imbricated. Hairs on antennae blunt; longest hair on 3rd segment 18-20 long, 0.64-0.73 times as long as articular diameter of segment; longest hair on basal part of 6th antennal segment 0.79-1.00 times as long as articular diameter of basal part of segment. Secondary rhinaria elliptical or almost rounded, projecting, with sclerotized rim and convex membrane. Rostrum reaching abdominal segment I. Ultimate rostral segment with 8 long accessory hairs. Legs strong, hind femora and hind tibiae 0.36 and 0.66 0.67 times as long as body, respectively; inner sides of hind coxae with rows of small spinules sometimes partially fused and forming scales; outer sides of hind coxae, trochanters, femora and tibiae smooth; 2nd tarsal segments imbricated. Hairs on legs pointed or, rarely, blunt; ventral hair on hind trochanter 0.47-0.52 times as long as basal diameter of hind femur; longest dorsal, ventral and dorso-apical hairs on hind femur 2023, 23-25 and 20 long, respectively; longest dorsal hair on hind tibia 1.00-1.07 times as long as mid-diameter of the latter. First tarsal segments with 3,3,3 hairs. 2nd segment of hind tarsus 3.504.00 times as long as its maximum width. Siphunculi distinctly swollen (diameter of the swollen part near apex 1.88-2.06 times the smallest diameter of the basal half), with distinct flanges, surface of siphunculi smooth, weakly wrinkled at base. Hairs on anal plate finely pointed. Cauda elongate-triangular, with 6 finely pointed hairs.

Measurements. Body - $1472 \times 609$, antennae 1844: III - 521, IV - 263, V-223, VI - 73+599; hind trochanter+femur -628 , hind tibia -974 , siphunculus - $283 \times 78$; cauda $-124 \times 111$ (at base) $\times 94$ (before base).

Oviparous female. Elliptic. Colour when alive dark brown, shining; antennae, femora (except bases), apices of tibiae and tarsi black; siphunculi and cauda dark brown. Cleared specimens with dark brown antennae, apices of femora, bases and apices of tibiae and tarsi, brown head, 3rd and 4th rostral segments, legs, arms of mesosternal furca, bands on segments of thorax, abdominal shield, bands and sclerites on abdominal tergites V-VIII, marginal maculae, peritremes, ante- and postsiphuncular sclerites, siphunculi, subgenital and anal plates and cauda. Dorsal surface of thorax with broad bands on all segments. Abdominal dorsum with large shield on tergites I-IV, two sclerites on tergites V and VI, short bands on tergites VII and VIII, large marginal sclerites on tergites I-IV, ante- and postsiphuncular sclerites and peritremes. Surface of head, thorax and abdominal tergites I-VI weakly wrinkled, almost smooth, of abdominal tergites VII and of postsiphuncular sclerites with rows of small, pointed spinules, which are on tergites VIII partially fused; surface of ventral side of thorax smooth, of abdomen with long rows of small pointed spinules. Hairs on dorsal surface of thorax and abdomen weakly capitate, capitate or blunt, on ventral surface of thorax and abdomen pointed or finely pointed; longest dorsal, marginal and ventral hairs on abdominal tergite III $30-33$ (32), 33-38 (34-38) and 35-40 (35-39) long, $1.00-1.37$ (1.05-1.33), $1.25-1.40$ (1.31$1.38)$ and $1.17-1.60(1.22-1.59)$ times as long as articular diameter of 3rd antennal segment, respectively; abdominal tergite III with 6-7 (6.7) dorsal hairs; tergite VI with 4 hairs between siphunculi; tergite VIII with 7-9 (8.0) hairs, longest hairs 40-46 (43) long, 1.42-1.89 (1.48-1.75) times as long as articular diameter of 3rd antennal segment. One specimen has one marginal tubercle on abdominal segment IV. Spinal tubercles absent. Head without epicranial coronal suture. Antennal tubercles not high, diverging; surface of antennal tubercles smooth; median tubercle weakly developed; frons moderately concave; ratio of depth of sinus to distance between bases of antennae 0.08-0.09 (0.08). Occipital and frontal hairs blunt; longest occipital and frontal hairs 28-38 (33-35) and 25-30 (25-28) long, 1.10-1.58 (1.22-1.34) and 0.83-1.26 (0.87-1.16) times as long as articular diameter of 3rd antennal segment, respectively. Antennae 6-segmented, 3rd antennal segment with 10-18 (10.0-17.0) secondary rhinaria situated in row all over posterior margin of segment, 4th segment with 0-4 (0.54.0), 5th segment without rhinaria. Surface of $1 \mathrm{st}$ 2nd antennal segments weakly wrinkled, of 3rd segment smooth with small scales at base of segment, of 4th segment weakly imbricated, of 56 th segments imbricated. Hairs on antennae blunt; longest hair on 3rd segment 23-28 (23-27) long, $0.75-1.10(0.78-1.08)$ times as long as articular diameter of the segment; longest hair on basal part of 6th antennal segment 1.00-1.14 (1.031.14) times as long as articular diameter of basal part of the segment. Secondary rhinaria elliptical or almost rounded, projecting, with sclerotized rim and more or less convex membrane. Rostrum reaching abdominal segments I-II. UI- 
timate rostral segment $1.93-2.64$ (1.93-2.48) times as long as its basal width, with 8 long accessory hairs. Legs strong, hind femora and hind tibiae 0.35-0.36 (0.36) and 0.65-0.68 (0.66) times as long as body, respectively; inner side of coxae with rows of small spinules sometimes partially fused and forming scales; trochanters, femora, tibiae and outer side of hind coxae smooth; 2 nd tarsal segments imbricated. Hairs on legs blunt or pointed; ventral hair on hind trochanter 0.48 $0.61(0.51-0.57)$ times as long as basal diameter of hind femur; longest dorsal, ventral and dorsoapical hairs on hind femur 25-28 (26), 25-28 (27) and 15-23 (18-21) long, respectively; longest dorsal hair on hind tibia 1.06-1.25 (1.16) times as long as mid-diameter of the latter. Hind tibia with 32-56 (34.5-52.5) rounded pheromone plates. First tarsal segments with 3,3,3 hairs. 2nd segment of hind tarsus 3.78-4.56 (3.89-4.56) times as long as its maximum width. Siphunculi distinctly swollen (diameter of the swollen part near apex 1.75-1.95 (1.88) times the smallest diameter of the basal half), with distinct flanges; surface of siphunculi smooth, of base of siphunculi weakly wrinkled. Subgenital plate oval, with weak constriction along medial line, with 6-11 (8.0-11.0) pointed hairs on anterior half and 12$23(13.0-23.0)$ hairs along hind margin. Hairs on anal plate finely pointed. Cauda finger-shaped, slightly narrowed to apex, almost elongate-triangular, with 7-8 (7.3) finely pointed hairs.

Measurements. Body - $1665 \times 883$, antennae 2029: III - 523, IV - 307, V - 255, VI-116+647; hind trochanter+femur -701 , hind tibia - 1096, siphunculus - $354 \times 99$; cauda - $147 \times 129$ (at base) $\times 96$ (before base).

\section{Acknowledgements}

The authors thank the administration of the Lapland State Biosphere Nature Reserve for financial and organizational support of field investigations conducted by A.V. Stekolshchikov in 2004-2005. The authors are appreciated to Dr. J. Holman for the opportunity to examine material from the aphidological collection of Institute of Entomology, Czech Academy of Sciences (Ceské Budéjovice, Czech Republic) and numerous consultations. This study was supported by the Russian Foundation for Basic Research (grant no. 04-04-81026-Bel2004a) and Byelorussian Republic Foundation for Basic Research (grant no. B04R-057).

\section{References}

Bbrner, C. 1939. Neue Gattungen und Arten der mitteleuropaischen Aphiden-fauna. Arb. physiol. angew. Entomol., 6: 75-83.

Borner, C. 1952. Europae centralis Aphides. Die Blattlduse Mitteleuropas. Schrift. Thuring. Landesarbeitsgemeinschaft f. Heilspflanzenkunde u. Heilspflanzenbeschaffung in Weimar, Heft u. Mittell. Thuring. Bot. Ges., 3(1, 2): 1-259, $265-484$.

Borner, C. \& Franz, H. 1956. Die Blattlęuse des Nordostalpengebietes und seines Vorlandes. Oster. zool. $Z, 6(3 / 5): 297-411$.

Heie, O.E. 1976. Masonaphis lambersi MacGill. og andre for Danmark nye bladlus (Homoptera, Aphidoidea). Entomol. Meddr., 44(1): 3-8.

Heie, O.E. 1992. The Aphidoidea (Hemiptera) of Fennoscandia and Denmark. V. Family Aphididae: Part 2 of tribe Macrosiphini of subfamily Aphidinae. Fauna Entomologica Scandinavica, 25. Scandinavian Science Press, Klampenborg. 189 p.

Itharco, F.A. 1979. Algumas espécies de afideos novas para Portugal continental (Homoptera, Aphidoidea). Bolm Soc. Port. Entomol., 3: 1-20.

Shaw, M.W. 1964. A basic list of Scottish Aphididae. Trans. Soc. Brit. Entomol., 16(2): 49-92.

Stroyan, H.L.G 1957. Further additions to the British aphid fauna. Trans. $R$. entomol. Soc. (London), 109(11): 311-360.

Received 24 April 2006 